\title{
Main Institutions Dealing with Property Right Protection and Crucial Issues Related to Them
}

\author{
Tanusha Selimi \\ European University of Tirana
}

\begin{abstract}
This writing analyzes the Institutions that enable procedurally and functionally the property right protection and its effectiveness. All the institutions in this writing have been analyzed according to the laws of the relevant time. Part of this writing is dedicated to the effectiveness and protection of property titles.
\end{abstract}

Keywords: ownership title, relevant institutions, law protection

\section{Introduction}

The analysis of the property right legislation, necessitates likewise the treatment of the relevant Institutions which have been specifically established to assist in this process. To this end, a professional and centralized agency has been founded in order to manage the legalization process. The amended law on legalization, established the Agency on Legalization, Urban Planning and Integration of the Zones/Informal Constructions. (ALUIZNI). This Agency is entitled to functions exercised as related to (mainly the urbanization and registering of the legalized properties.) and exercised by other bodies as well.

ALUIZNI has been given the mandate to process the legalization applications as well as to coordinate the legalization process. The ALUIZNI operational instructions, cover the legalization procedures, qualification criteria on the informal objects, procedures on issuing legalization permission, as well as the initial registration of the property title from the ZRPP.

ALUIZNI, on the other hand deals with the property title research, identifies the informal properties, approves the borderlines and prepares the legal and technical documentation for approval from the government. After the case processing, ALUIZNI presents to the government, the project decisions in groups.

Finally, ALUIZNI deals with the urban planning sectors at the local government units for the preparation of the urban planning for zones that have undergone legalization 
process. If the zone where a building is located is not initially included in an urban planning, the property cannot be legalized. The legalization was a pragmatic response to the dire and growing consequences due to illegal occupation and unlawful mass migration. When confronted with the issues of this kind, the governments in general have nothing to do but to accept the reality and to legalize the property usage. The legal framework for this approach was replaced in 2006 with the law on Legalization, Urbanization and Integration of Illegal Construction which due to the amendments and changes made, foresees a mechanism for the legalization of the illegal constructions and illegal extensions and creates a system for the urban planning.

This Law establishes as well a mechanism for transfer of the property title to the applicant on the land where the illegal object has been constructed and includes a compensation right for the ex-owners as well as a formula for the calculation of the compensation. In order to treat this issue, ALUIZNI comes forward with a proposal to expropriate the private property by transferring it to the state and after it becomes state property (via a government decision), in order to later transfer it to the applicant for legalization. Afterwards the property title may be registered at the ZRPP. The owners of the properties illegally occupied have filed lawsuits in the court considering this decision as anti-constitutional but the Constitutional court decided that the expropriation method for the transfer of land to the illegal land occupants is permissible treating essentially the legalization as a process of public benefit.

Some other amendments and changes in the legalization Law made in 2008 simplified the administrative procedures in order to ensure the legalization of the land and construction of the building on the relevant land simultaneously, consequently synchronizing compensation payment to the expropriated land owners.

\section{Discussion}

Nevertheless, in practice, not all the expropriated owners have received the relevant compensation regarding the legalization process. This means that the highest percentage of legalization should be covered by the State budget sources. Irrelevant of this deficiency, in October 2009, amendments and changes have been approved in the Legalization Law which enable the applicants to pay almost half of the legalization cost, as for the other part they may use the privatization bono stocks which can not be used otherwise. Nevertheless, the lack of tariff payment by many applicants on the legalization for the finalization of the legalization process creates an obstacle. The legalization process has been slow despite the resources offered. 
ALUIZNI is a big organization and well equipped with resources, and operational costs which are covered by the state budget. The Agency has technical expertise for topography observation, map preparation, legal and urban aspects and it has produced modern computerized maps for the entire country based on aerial photographs taken in 2006. ALUIZNI has produced computerized maps for the majority of the properties for which legalization application has been presented. Nevertheless, only a small percentage of property legalization which property titles have been registered by the ZRPP has been accomplished. According to the reports, the legalization has been prevented by issues arising from the coordination of work between ALUIZNI, ZRPP and AKKP.

First of all, there are issues regarding the data. Standardization. The ALUIZNI geographic data, which have been produced based on the most recent technology on aerial photography and GPS (Global Positioning System), are based on a more accurate and recent technology as compared to that of the ZRPP. The ZRPP notes are based on older paper maps and topography observation methods which are less accurate. ZRPP has only recently started to accept the ALUIZNI map data. Previously, ALUIZNI used to provide topography data at a scale of 1:1000 and ZRPP used to manually convert this information at a 1:2500 scale and used to transfer it on the paper maps. This method used to slow down the process and reduced the data usage and efficacy. Secondly, the compensation payment on expropriation for legalization purposes, remains uncovered with sufficient funds. AKKP reports that neither ALUIZNI nor the State budget have allocated the required amount of ALL 4.5 billion needed to pay the required compensation based on the legalization decisions which have been presented by ALUIZNI. This results in the possibility for non-compensation of former owners, which may bring about the invalidation of expropriation decisions proclamation. The continuous legalization process excludes a series of objects illegally constructed. Furthermore, the number of illegal constructions is on the rise. The ongoing illegal constructions (because of the builders' own decisions or because the urban planning system does not function properly). As a consequence, a considerable number of properties, remain out of the legal market of real estate property, consequently objects illegally constructed excluded from the legalization process remain exposed to the demolition risk.

Every new wave of legalization shall be accompanied by trustful measures for the prevention of the new illegal constructions. Consequently, it is imperative that the government manifests care for the implementation of every new wave of legalization to be accompanied by a trustful program of the obligatory enforcement of the 
existing legislation for construction control as well as by undertaking strong efforts to prevent the illegal construction prior to its start. It is worthwhile mentioning as well that not all the buildings shall be legalized given that some of them have been built in unsuitable zones for construction such as the protected environmental zones, heritage trail spots as well as zones which constitute security risks such as the zones vulnerable to floods. Every new privatization wave shall be closely reviewing the expropriation method as well, given that it may trigger further illegal land occupation.

Given that there is a small number of properties that can be directly transferred to their initial owners, the recent process is now dealing more with the compensation payment. As regards to the policy content, the Law on the Land Restitution and compensation as approved in 2004, follows a similar approach to that of the Eastern and southeastern European countries. Yet the request to compensate the owners with the current market value is difficult to be implemented given the high fiscal costs. The Land restitution and compensation may not be considered as isolated from the privatization and legalization process.

During the privatization process, the buildings and small enterprises were privatized and transferred to the relevant owners but the land whereby the buildings have been constructed might have been transferred to other individuals in the framework of the property transfer process. The land around the residential buildings was often privatized by the apartment owners, irrelevant of the fact that it might have not been the object of requests for property restitution. The properties where buildings have been illegally constructed cannot be restituted to the initial owner while in the course of the privatization process. This right pertains to the citizens. Ever since 2006 AKKP has been accountable for the implementation of the restitution and compensation process. In 2006, the amendments and changes to the Law of Restitution and Compensation, created AKKP and transferred to this Agency all functions of restitution and compensations which in the past were the responsibility of the Central Government and the local commissions. These amendments and changes aimed at the increase of the efficiency and rhythm of this process, but these expectations have not yet been met. The expertise needed from the AKKP staff includes mainly the topography and legal knowledge. The human resources of the Agency are generally sufficient for covering most of the areas but what is lacking is the necessary transportation means for field visits, as well as modern and contemporary computer means and technology of information support. The AKKP maps are mainly paper maps given that they have not received the computerized maps from other agencies such as ALUIZNI but even if they had these 
maps, the IT infrastructure and the staff training of the AKKP lacks the required expertise level to deal with them. Like in the other areas, a small percentage of compensation applications treated by the AKKP, has been paid, given the lack of funds. The law on the Restitution and Compensation, foresees different compensation methods, including the state property transfer at the same amount if the transfer of the original property is impossible. The slow compensation process may be the cause for the low level of public trust in AKKP.

The government must accelerate the compensation of the expropriated owners, in order to respect its own political engagements, the legal citizen rights and improve the functioning of the property markets.

The rising number of the verdicts of GJEDNJ against the Albanian authorities, regarding judicial issues on property rights, may bring about the collection of considerable amounts for the compensation to be paid by the state, ruining thus the international image of Albania. Furthermore, the lack of private property protection as guaranteed by the international legislation is considered by the GJEDNJ, as violation of human rights and freedom, constituting in such a way an obstacle for Albania's accession into the EU.

Possibility must be given to as many applicants for private property requisition by at leas providing them a partial compensation within a short period of time while the long-term options for covering the compensation cost are dealt with through a permanent mechanism.

The legal framework should be reviewed in order to provide compensation at market value given that it is clearly observed that it can not be affordable financially and is not in compliance with the international practice. Some of the Central European countries have passed the legislation on the land restitution for properties confiscated during the communist regime and payment of compensation to the expropriated owners whose property cannot be restituted, but the Albanian law is the only one requesting compensation based on the current market value.

Even though reforms have been undertaken continuously, the service quality and organization method need to be improved. Currently the initial registration of the real estate properties is almost being finalized. Relevantly the digitalization of the title card and the maps reflecting the initial property registration has started but it is imperative to digitalize all the later transactions performed, as well as the establishment of a state electronic database which may be of service to other operators needing this information. Improvement of the material resources and work environment is needed. the ZVRP's have undertaken the responsibility to serve 
other agencies such as AKKP, the regional tax offices, the courts, the prosecution, the bailiffs, ILDKP-s but there is no payment provided for offering these services.

These services affect and render unsuitable their capacity to cover the main responsibilities and duties. The documentation used for registration is often deficient and prevents the continuation of the procedures of initial registration. Until recently the ZRPP performs its duties sufficiently with average quantitative indicators and its restructuring of its own activities towards self-financing needs diligence in order not to ruin the successes achieved so far regarding the basic functions.

Recently a new law has been passed, number 33/2012 for the real estate property registration which reforms the organization of the ZRPP as a refinanced institution. It establishes principles for quick and efficient registration procedures, it allows the registration of properties constructed prior to 1991considerably limits the right of the ZRPP for limitation on registered property, establishes rules for data improvement and update as well as it

guarantees the information provided by the ZRPP11. This Law establishes a safe future of the ZRPP towards online services according to the economic business principle "one stop shop", safe registration of the property titles and establishment of a portal for the citizens requesting services for real estate property registration. ${ }^{2}$ The property market functioning has been damaged by the lack of the property title registration for those individuals purchasing an apartment on a building that has not yet been finished. When a contract is signed for the purchase of an apartment on a building that is not yet constructed, the buyer gives the constructor a considerable amount of money for example EUR 50000 to EUR 60000 but the contract can not be registered as related to the property (if we suppose that the property itself is already registered).

Consequently, the buyer has no guarantee at all. There is consequently a clear possibility of economic fraud through multiple selling of the same apartment to

\footnotetext{
1 The Law No. 7843 was aproved on 13.07.1994 "On the registration of the real estate properties" and amended by Law 8090, dated 21.03.1996, number 9407 dated 19.05.2005, 9701, dated 02.04.2007 For the establishment of the sturcture, functioning of this system as well as to define the conditions, the registration methods organization as well as every procedure related to the registration. In such a way the real estate property registration as well as real rights on them are registered based on the provisions of the civil code of the specific laws on the mode of acquiring ownership as well as in the organic law.

2 See J. Gergi-S. Bana, "A general overview on the practice of real estate property registration as a necessity for guaranteeing the rights of the individual on the property", the magazine JUS\& JUSTICIA , number 3, Tirana 2009
} 
multiple buyers. Currently, the people are based on the traditional personal relationship existing between individuals and not on the registration of real estate properties.

The ZRPP capacity, the human resources and the service quality have been improved in the recent years but other efforts are needed to be undertaken in order to empower the staff skills and in order to further upgrade the efficiency of the ZRPP, a Chief Registrar is managing this agency with 35 offices in the entire country, more than 550 employees, who are lawyers, topographers, economists and administrative staff. ${ }^{1}$ The rate of the staff dismissal is high and the latest training has been undertaken at the end of the nineties. It is not a surprise that ZRPP customers oftentimes complain that the staff is not acquainted with the system details even though the surveys undertaken recently by the ZRPP demonstrate that the customers are more satisfied.

The data quality improvement remains a major issue for the ZRRP. As above mentioned, the geographic data are oftentimes erroneous with a margin error of 1 to 10 meters in some maps. Although a high percentage of the ZRPP are considered as incorrect, they are considered "legal maps". The recent use of the computerized maps as produced by ALUIZNI, in the framework of the ongoing and systematic registration undertaken upon the support of the LAMP, is a positive step undertaken for the data quality improvement. Even the legal data are considered disputable in many cases which obliges the institutions and economic units of the private sector utilizing these data, spend a lot of time of their own staff in order to treat the lack of compliance. ${ }^{1}$ The ZRRP's should have taken a systematic approach for the improvement of the registration data starting with the most crucial needs regarding the economic growth. ${ }^{2}$ Besides, the ZRRP could have applied methods of

\footnotetext{
1 Based on the law number 7843, dated 13.07.1994, " on the registration of the real estate properties', as amended, on the registration of the property titles and other real rights on real estate properties, as well as for the preparation, maintenance and management of the real estate registers, demonstrating registration maps and documentation which testify the property right and other real rights on the real estate property , the office of the Registration of the real estate properties was established. These offices were established upon the decision of the Council of Ministers number 596 dated 21.09.1998 "On closure of the hypothecary offices and their transfer of their activity into the Real Estate Registration offices. Based on the decision of the council of ministers number 556 dated 23.10.2000, " On the delivery of the property documentation to the offices of the real estate property registration, all the state institutions which based on the specific law issue property titles, or have property documents such as the cadaster sectors, offices of the national registration offices, KKK of owner properties the National Entity of Residential Dwellings in districts as well as other institutions are obliged to deliver these documents to the offices of the real estate property registration.
} 
a lower cost for the initial, sporadic registration in order to render this process more efficient and attractive to the owners. ${ }^{3}$

Irrelevant of the recent progress, ongoing efforts need to be undertaken in order to achieve transparency growth and to improve the customer perception on the ZRRP. The low quality of the existing title cards, some legal lack of legal or procedural clarification which affect the registration of the property titles for some kinds of properties, and the insufficient staff training, have brought about an insecurity and frequent lack of compliance in the way different ZRPP offices treat the applications for title registration which in itself renders the terrain for corruption 4 more fertile.

Consequently, the ZRPP offices are considered as most predisposed for corruption at low sums of money at local government level. In order to react to this issue, the ZRPP has recently undertaken initiatives in order to improve the transparency in order to achieve customer satisfaction from its services and to minimize corruption. Since 2009, ZRPP, conducts surveys on the level of the customer satisfaction in order to collect customer impressions on the service quality level so much so that the latest survey demonstrated a rather improvement level of customer satisfaction from the service quality and ZRPP honesty.

ZRPP publishes online information on its site on the activities, procedures, tariffs, complaint mechanisms and other issues of interest to the public. Since 2010, the ZRPP has established communication channels including a special telephone number whereby the public may manifest its worries and complaints as regards to the ZRPP services, accusations on corruption included. Finally, it has empowered its internal tools for institutional integrity, and coordination with other relevant institutions responsible on the fight against corruption and economic crime, money laundering included. 5

\section{Conclusion}

It is worthwhile mentioning here another institution of crucial importance in this field. The Council of Ministers is the most important body in the country which via the legal acts and bylaws defines and solves concrete situations following the implementation of the law number

9482 " On the legalization, urbanization and integration of illegal constructions" as amended. The organizational and functioning mode of the Agency on the legalization, urbanization and integration of the informal zones/constructions, of the Central 
Directorate, directorates at regional level and offices of special units of the local government are defined by the Council of the Ministers.

The Council of Ministers has the competence to cancel the implementation of the procedures for the legalization of the illegal constructions in territories with a high level of environmental pollution as well as to implement or plan strategies for the elimination of the environmental pollution in the zone according to concrete deadlines. Likewise, regarding the illegal constructions for residential functions when the individual is unable to pay, the Council of Ministers, relevant to the declared cases, defines alternative options and procedures for the amount payment of the plot.

The council of Ministers defines the criteria and procedures for the coordination of activities on the identification of these individuals via the state committee on the property restitution and compensation and local government units and ZRPP.

\section{References}

[1] Article 17/5 of the Law number 50/2014 "On some amendments and additions in the Law number 9482, dated 3.04.2006 "On the legalization, urbanization and integration of illegal constructions".

[2] Article 46 of the Law number 50/2014 "On some amendments and additions in the Law number 9482, dated 3.04.2006 "On the legalization, urbanization and integration of illegal constructions".

[3] J.Gergi-S. Bana "A general overview on the practice of real estate property registration as a necessity for guaranteeing the rights of the individual on the property",", the magazine JUS\& JUSTICIA , number 3, Tirana 2009

[4] Qafa A 2017 “The Property Right", Tirana [5] Qafa A 2017 "The Property Right”, Tirana [6] Qafa A 2017 “The Property Right”, Tirana 